\title{
New Explanations to Law of Resource Utilization Yiming Cai ${ }^{1, a}$ \\ ${ }^{1}$ Adjunct Professor of School of Management, Zhejiang Ocean University, China; Senior Economist of Zhoushan Port Authority, Zhejiang, China \\ acym877@126.com
}

Keywords: resource, space, depth and breadth, time model, relativity.

\begin{abstract}
The serious problems of resources and environment arising in development of human society have important ties with the scientific understanding of mankind toward the law of resource utilization. The author has demonstrated, based on the division of human resource utilization in depth and breadth spaces, the material form and nature of the depth and breadth space resources; and put forward the time model of the depth and breadth space resource utilization — a time demarcation and analysis of human resource utilization, with which we can see in the other sphere the various states of the influences of resource utilization by mankind to the environment. The continuous extension and utilization of depth space resource at one point is the core content of new explanation to resource utilization in phenomenon of "work". The time model of the breadth space takes the carbon cycling as the example and divides the resource material cycling into three stages. The analysis by the author offers us an audio-visual and comparatively new "cross-section" in the research of depth and breadth space resource utilization, also a new and systematic explanation to the law of resource utilization.
\end{abstract}

\section{Introduction}

Hawking, the British theoretical physicist, is repeatedly reported recently. According to Hawking, the extraterrestrial life most probably exists in forms of microorganism or elementary organism, but cannot rule out the existence of intelligent organism with threats to mankind. He also concludes that certain high-class intelligent beings may plunder global resources. It is thus clear that the resources are the common grave matter in the course of social development of the globe and intelligent extraterrestrial beings (if it is so). The advance of the theory of depth and breadth space resources provides new theoretical proof for harmonious and scientific development in utilizing and solving global and outer space resources problems by mankind.

The theory of "ocean development" on breadth and depth space put forward by the writer in 2011 was accepted by the international academic circle and the essay of the writer was published in full On Breadth and Depth Space for "Ocean Development" in TELOS Volume V -Special Edition in honor of Guido de Marco, ex-president of Malta. [1] Some of his academic opinions were also released in international academic periodicals. [2]

\section{Breadth and depth space of resources}

In exploration and utilization of energy or other resources by mankind, it is divided into breadth and depth spaces, the re-acknowledgment and clarification of development, utilization and exploration of space of energy resources is of importance to solution of resource and environment problems.

The exploration and utilization of energy or other resources by mankind can be divided into breadth space (horizontal) and depth space (vertical) in a coordinate. The breadth space is plane, extending ceaselessly on the horizontal "line", in unlimited "breadth"; resource area of energy in horizontal breadth space has limited resources and not recoverable as without "depth", such as coal, oil etc. Depth space is continuous vertical extension "at one point" of a "line" of breadth space and energy resources are obtainable inexhaustibly with unlimited "depth", such as solar energy, wind power. Besides, "point to point" recollection of scrap iron and steel, glass, petrochemicals etc on land can also be combined into depth space for development and utilization. 
After comparison and research, it is found that the basic laws in human's resource utilization can be analyzed and shown by a cross coordinate( Figure 1 and Figure 2).[3]

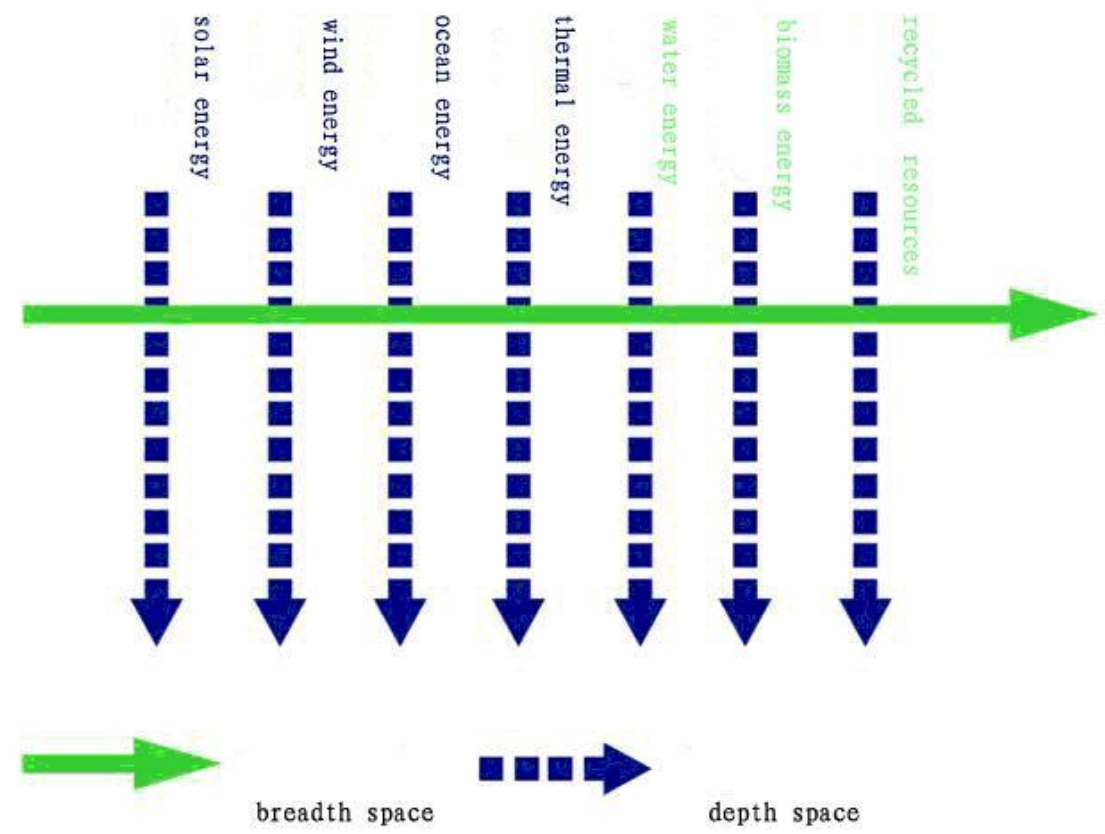

Fig. 1. Breadth and depth space relationship diagram of energy and other resources

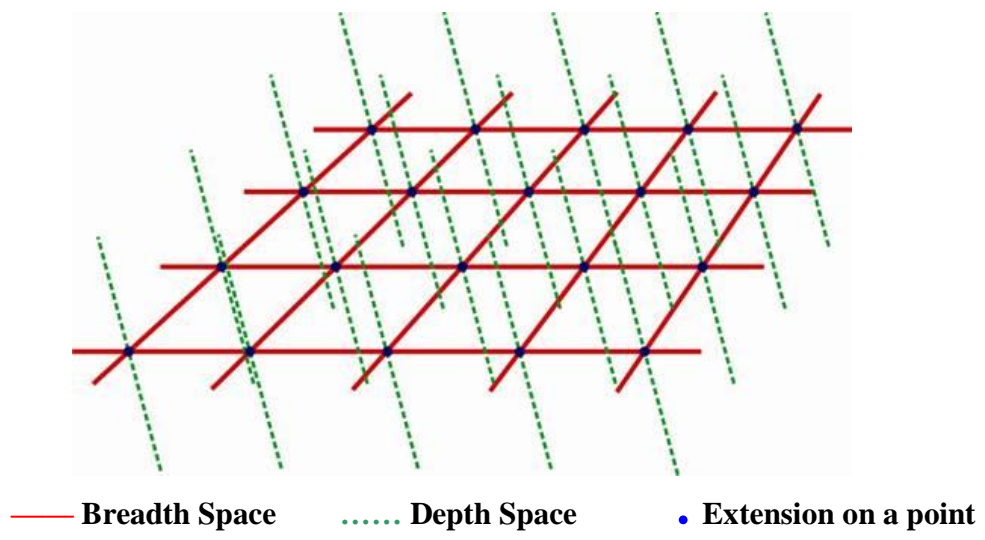

Fig. 2. Three-dimensional diagram of breadth and depth space

\section{Main features of depth space resources.}

The exploration of depth space energy and other resources can be characteristic as the continuous extension and "copying" of "one point".

Depth space resources exist both on land and in ocean. The concept of depth space and control power of depth space contains the outer space___ "new ocean" too.

Both the breadth and depth spaces have a feature of infiniteness. The breadth space "unlimitedly" extends from the micro space to land, ocean and "new ocean". The resources of depth space such as solar energy, plant energy, and renewable energy etc. are also inexhaustible in "infinite" depth. 


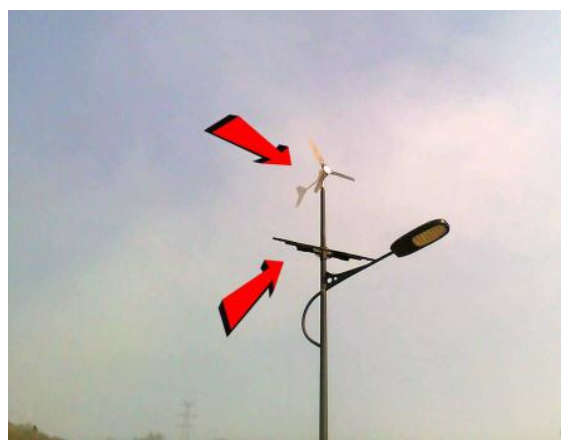

Fig. 3. Lamp assembly of wind power and solar energy along the street.[4]

Resources as depth space energy are utilized mostly by continuous extending and copying at one point. For instance, solar energy, wind power and geothermal energy are resources unlimitedly obtainable at one point. Plant energy is also a sort of resource planted, harvested and obtained at one point, running in cycle.

The first law of depth space resource utilization is, the energy generated in nature is utilized to work directly and extend, without changes to its material structure of natural attribute of the working energy.[5]

Plant energy is another form of utilization at the "point" of depth space resources. The utilization at one point of depth space plants keeps the balance of motion of matter in natural world through absorption and emission of chemical substances by plant energy and other resources.

The second law of utilizing depth space resources is: by utilizing the work and extension of resource "point" and going through the reasonable period for circulating and recovering of resource "points", the balance between resource utilization and mature and ecology is achieved. [6]

The time concept of depth space theory suggests the time concepts of depth space resource "point", "point circulation" and "point and point" circulation.

The time concept of depth space resource means for power naturally generated through utilizing the nature to work directly, being direct, fast and cleanest.

The time concept of depth space plant resource utilization point circulation stands for the cycling time in its life through absorption of chemical substances as carbon dioxide by plant resources and emission after utilization by mankind through production, re-absorption and re-emission. The absorption and emission of hazardous gases and chemical substances by plant resources is almost equal, so to keep the ecological balance of the natural world and to bring little affects to the living conditions of mankind and the nature. The time concept of plant resource point circulation includes forms of energy plant point circulation and other plant resource point circulation.

The time concept of point circulation may also fall into the three aspects of time concepts of energetic plant "point circulation", metal resource plant "point circulation" and other resource "point circulation".

The time concept of depth space point and point resource circulation means that mankind, in the course of utilizing renewable resources (scrap steel, glasses etc.), apply recycling use of renewable resources to reduce consumption of resources and energy and do their best to control the emission of hazardous gases and substances as $\mathrm{CO} 2$ in the reasonable circulation periods with no or little affects to human life and natural environment.

\section{Main features of breadth space resources}

Breadth space resources mainly refer to coal, oil, natural gases and other energy resources.

The material forms and chief natural features are: the materials remain in relatively stationary or sleeping states. Coal, oil and natural gases remain in relatively stationary states in the breadth space before they are utilized by mankind. Their energy forms and nature are chemical energy. The molecular structures of these resources of coal, oil and natural gases are changed as utilized by mankind, leading to the imbalance of the natural environmental circulation and destruction of the ecological environment. 
The breadth resource space is the continuous "extension" of the "plane" of "a line".

\section{Time Mode of Resources Space}

Table 1.Time Mode of Depth Space Resources

\begin{tabular}{|l|l|l|}
\hline Time Term & Time Concept, Characteristics & Impact on Environment \\
\hline "Piont" & $\begin{array}{l}\text { Use energy produced by nature to } \\
\text { do work directly, Physical work } \\
\text { Type: Solar energy, wind energy, } \\
\text { wave energy, etc }\end{array}$ & $\begin{array}{l}\text { Basically no pollution } \\
\text { Cleanest }\end{array}$ \\
\hline "Point Circulation" & $\begin{array}{l}\text { Circulation time process of } \mathrm{CO}_{2} \\
\text { absorption, emission after } \\
\text { utilization and re-absorption by } \\
\text { plant resources } \\
\text { Reasonable period circulation, } \\
\text { chemical work } \\
\text { Type: Energy Plants, Metallic } \\
\text { resource plant, other resource } \\
\text { plants }\end{array}$ & $\begin{array}{l}\text { Relatively little impact in } \\
\text { reasonable period if } \\
\text { number of resource plant } \\
\text { is well controlled }\end{array}$ \\
$\begin{array}{l}\text { Circulation and reutilization of } \\
\text { steel, glasses, etc. } \\
\text { Utilize the unchanged material } \\
\text { structure of living resources in } \\
\text { re-utilization circulation and } \\
\text { resources utilization, Chemical } \\
\text { Work } \\
\text { Type: Steel Scrap, Bronze Scrap } \\
\text { Aluminium Scrap, Wasted Glass, } \\
\text { etc }\end{array}$ & $\begin{array}{l}\text { Renewable resources will } \\
\text { consume part of resources } \\
\text { during living process. It } \\
\text { has relatively little impact } \\
\text { on environment if the } \\
\text { number is well controlled }\end{array}$ \\
\hline "Point to Point"
\end{tabular}

Table 2.Time Mode of Breadth Space Resources(takes the carbon cycling as the example)

\begin{tabular}{|c|c|c|}
\hline Time Term & Time Concept, Characteristics & Impact on Environment \\
\hline Short-term Phase & $\begin{array}{l}\text { The periodic time cycle in Earth's } \\
\text { outer layer of } \mathrm{CO}_{2} \text { and other } \\
\text { substances produced during } \\
\text { breadth space resources utilization. } \\
\text { Carbon reservation volume in } \\
\text { ocean is } 50 \text { times as much as that } \\
\text { in atmosphere. } \\
\text { The exchange of } \mathrm{CO}_{2} \text { between } \\
\text { surface sea and deep sea is very } \\
\text { slow. As per statistics of } \\
\text { UNESCO in } 1978 \text {, water exchange } \\
\text { cycle of global oceans is } 2500 \\
\text { years } \\
\text { Nature: Chemical Circulation }\end{array}$ & $\begin{array}{l}\text { Over discharged } \mathrm{CO}_{2} \text { into } \\
\text { atmosphere by human } \\
\text { can not be absorbed by } \\
\text { seawater in short term and } \\
\text { it will form a serious threat } \\
\text { to human survival. }\end{array}$ \\
\hline $\begin{array}{l}\text { Medium-term } \\
\text { Phase }\end{array}$ & $\begin{array}{l}\text { According to modern science, the } \\
\text { cycle between } \mathrm{CO}_{2} \text { and other } \\
\text { substances produced during } \\
\text { human's breadth space resources } \\
\text { utilization and fossil energy and }\end{array}$ & $\begin{array}{l}\text { Excess emissions of } \\
\text { polluting substances; } \\
\text { Environment human is } \\
\text { hard to survive or cannot } \\
\text { survive. If it needs human }\end{array}$ \\
\hline
\end{tabular}




\begin{tabular}{|l|l|l|}
\hline & $\begin{array}{l}\text { other resources or carbonate rocks, } \\
\text { etc. According to modern science, } \\
\text { this cycle takes thousands of years } \\
\text { to hundreds of millions of years. } \\
\text { Nature: Chemical Circulation }\end{array}$ & $\begin{array}{l}\text { society to wait } \\
\text { environment recovery of } \\
\text { circulation in thousands of } \\
\text { years and even millions of } \\
\text { years, such waiting time is } \\
\text { out of human's reach. }\end{array}$ \\
\hline Long-term Phase & $\begin{array}{l}\text { The long-term phase cycle of } \\
\text { breadth space energy and other } \\
\text { resources refers to the overall } \\
\text { cycle of Earth's substances. Why } \\
\text { we cannot find rocks older than 3 } \\
\text { billion years? The reason is all } \\
\text { substances in Earth crust have } \\
\text { circulated once. } \\
\text { Nature: Chemical Circulation } \\
\text { circulation over 3 billion } \\
\text { years is unreachable. }\end{array}$ \\
\hline \multicolumn{2}{|l}{} \\
\hline
\end{tabular}

\section{Time Concept Relativity of Depth and Breadth Space Resources}

This is a simple matter but neglected by people for a long term.

The utilization time concept of depth and breadth space resources is stated against influences on human living environment and natural environment in time. Depth space energies work and are utilized at one point without chemical reactions with other substances. It belongs to direct work. Therefore, it cut off the time links of pollution brought by chemical substance reaction on human society and environment. The work and utilization of plant energy and other resources point circulate continuously. The carbon and other substances absorbed are equal to those are released which includes the "degree" of substance cycle "content" and time that are acceptable to human society and natural environment, i.e. the influence brought by this cycle on human living environment and natural environment is controlled to a reasonable time period. The utilization of renewable resources from point to point is also for the purposes of saving resources and improving resources' reutilization, reducing the cycling time of "absorption" and " release", as well as reducing pollution.

The impacts of increasing growth of $\mathrm{CO} 2$ and other substances released by breadth space resources utilization on human living environment and natural environment, compared to the cycling time of "absorption" and "release" of utilizing depth space energy and other resources, from the short-term phase cycle of 500 1000 years from breadth space resources utilization to $\mathrm{CO} 2$ and other substances emission, to the overall cycle of 3 billion years for long-term phase cycle of Earth's substances, both are the distant and hopeless wait regarding to human's living environment influence.

Most of the normal and reasonable cycles to nature from a macroscopic perspective are not allowed for human's living environment.

\section{Acknowledgment}

Today the problems of resource and environment are considered as the most serious ones confronting human society in process of development. "Neo-explanation to laws of resource utilization" refers to a brand new interpretation to the environmental and resource problems. The author has studied this issue for several years and he is willing to be responsible for his new proposed academic viewpoints in this thesis. I appreciate extraordinary the assistance and support in translating this thesis into English from Prof. Xu Jianhua, Miss. Cao Yunhong, Mr. Liu Xiaojia and Mr. Luo Jiajia. 


\section{References and Notes:}

[1] Yiming CAI, On Breadth and Depth Space for "Ocean Development" [M]. TELOS - Special Edition in Honour of Guido de Marco $\mathbb{C}$ Fondation de Malte. Volume V, 2011:111-130.

[2] Yiming Cai. Depth Space and the Theory of Depth Space Control Power, [J]Advanced Materials Research Vols. 361-363. 2012. (C) (2012) Trans Tech Publications, Switzerland: 895-905..

[3] Yiming Cai. Depth Space and the Theory of Depth Space Control Power, [J]Advanced Materials Research Vols. 361-363. 2012. (C) (2012) Trans Tech Publications, Switzerland: p899.

[4] Yiming Cai. Depth Space and the Theory of Depth Space Control Power, [J]Advanced Materials Research Vols. 361-363. 2012. C (2012) Trans Tech Publications, Switzerland: p899.

[5] Yiming Cai. Material Form and Nature of Depth Space Resources , [J]Advanced Materials Research Vols. 524-527 (2012). (C) (2012) Trans Tech Publications, Switzerland: pp 3398-3402.

[6] Yiming Cai. Material Form and Nature of Depth Space Resources , [J]Advanced Materials Research Vols. 524-527 (2012). (C) (2012) Trans Tech Publications, Switzerland: pp 3398-3402. 